\title{
Evaluating the Quality of Hospitality and Tourism Education in Vocational Institute in China
}

\author{
Huawen Shen ${ }^{1}$, J. M. Luo ${ }^{2} \&$ C.F. Lam ${ }^{3}$ \\ ${ }^{1}$ School of Hotel and Tourism Management, The Hong Kong Polytechnic University, Hong Kong \\ ${ }^{2}$ Faculty of International Tourism and Management, City University of Macau, Macao \\ ${ }^{3}$ Department of Finance, The Chinese University of Hong Kong, Hong Kong \\ Correspondence: Kenny Luo, Faculty of International Tourism and Management,City University of Macau, \\ Avenida Xian Xing Hai, Ed.Golden Dragon Centre, $4^{\circ}$ andar, Macau. Tel: 1-853-8590-2241. E-mail: \\ kennyluo@cityu.edu.mo
}

\author{
Received: March 22, 2015 Accepted: April 27, 2015 Online Published: May 31, 2015 \\ doi:10.5539/ijms.v7n3p12 URL: http://dx.doi.org/10.5539/ijms.v7n3p12
}

\begin{abstract}
This paper examines the quality of the hospitality and tourism programs delivered by vocational institute in China in terms of six dimensions, i.e. curriculum and instruction, faculty, strategic planning, administrative management, student achievement and resources. It was revealed in the study that hospitality and tourism programme in vocational institute in China is facing a lot of issues and challenges such as scattering of resources, lack of qualified educators, recklessly expansion etc. Finally, the implications are also discussed.
\end{abstract}

Keywords: hospitality and tourism education, quality, vocational institute, China

\section{Introduction}

The tourism industry in China went through fast development after the implementation of economic reform in 1978. China has now become one of the most popular tourist destinations in the world. According to United Nation World Tourism Organization (UNWTO) (2012), China was ranked the top three in terms of intentional tourist arrivals. To cater for the needs and wants of increasing international tourists, the hardware of hotels, restaurants, airports and other tourist facilities were established and generally fulfilled international standard. However, Terry and Xiao (2000) pointed out the software dimensions, such as employees' service attitudes, skill levels, and language ability have not met international travelers' expectation. They explained the tourism industry in China developed so fast that the supply of quality managers and practitioners could not fulfill substantial demand from the industry.

Professional knowledge and skills can be developed thought various channels, such as government-sponsored or enterprise-sponsored training programs, trade associations, community colleges or universities (Barrows, 1999). Formal education is the mainstream. It prepares students who desire to work in one of the broad group of professions that make up the hospitality and tourism industry, which plays a crucial role in affecting the supply of talents in the future labor market. Vocational training is particularly important in this field of study because of the characteristics of the industry. This paper aims to evaluate the quality of hospitality and tourism programs in China in terms of the six quality standards identified by Horng, Teng and Baum (2009). Recommendations and insights are provided in the final section on how academic standard can be enhanced and what professional offerings can better suit the industry's needs in terms of six dimensions.

\section{Literature Review}

\subsection{Quality in Hospitality and Tourism Education}

Tourism is a fast growing industry in many countries, which creates a multiplier effect in economy and provides numerous job opportunities. According to the statistics published by UNWTO (2013), international tourist arrivals had reached 1 billion in 2012 and an upward trend was expected in the future. Because of the industry's continuous development and promising prospect, hospitality and tourism education grew from a small unit under traditional disciple (e.g., business or geography) to a separate and independent school in a comprehensive university. Diverse programs, ranging from the certificate level to postgraduate level, were rapidly developed 
since then.

The supply of hospitality and tourism education is increasing; however, the pool of prospective students is shrinking due to the trend of low birth rate (Chang \& Hsu, 2012). Besides, parents and students nowadays are more sophisticated and demanding. As a result, quality pursuit and assurance make institutions stand out in increased competition. The concept of education quality borrows from business community (Fenich, 1999). To achieve the goal of education excellence, total quality management (TQM) must be implemented. In business management, TQM is a system widely used to help organizations to continuously improve their work process, products and services by evaluating and comparing objectives and outcomes, with the set goals. Following the same logic, TQM ensures that the quality and value that education institutions deliver to students match with their stated goals and objectives. Fenich (1999) defined quality assurance as:

An organization must define itself, as through a mission statement and then set goals and objectives that will support that mission before it can hope to measure its outcome again the stated goals (p.68).

Quality has no absolute standard. What constitutes a quality product rests on the expectation of the target customers, their needs and wants and the offer of competitors (Grönroos, C. (2007). In this sense, the quality of a bed and breakfast, charging $\$ 500$ per night for a room for two people, is not definitely lower than that of a deluxe hotel, charging $\$ 2500$ per night per person. In a similar fashion, the parameters used to gauge the quality of an education institution depend on how it defines itself, its program portfolio, and the expectations it creates in its students' mind (Fenich, 1999).

It is also important to note that education quality is multi-dimensional and cannot be assessed by a sole indicator (Cheng \& Tam, 1997). According to Cheng (1995), the conception of education quality involved the elements in the input, process, output of education system and the services the education system delivered to its internal and external constituencies. In addition, the relative importance of each indicator might be different from institution to institution. Some may particularly focus on the quality of inputs to the education systems; whilst, some emphasize more on the quality of outputs. Cheng and Tam (1997) explained that the variation in the selection of and the emphasis on indicators result from the diverse interests and anticipations among the related constituencies and the different management strategies implemented to accomplish education quality under a given environmental setting and within a given time frame.

Several researchers attempted to define quality in hospitality and tourism education. As proposed by Cheng (1995), quality can be assessed in terms of three broad dimensions: input, process and output. It can also be evaluated by seven more specific criteria: a) excellence, b) threshold, c) fitness for purpose, d) fulfillment of an institution's aims and objectives, e) meeting customer requirements, f) transformation, and g) value for money (Harvey \& Green, 1993). No matter how quality is defined, its evaluation often connects to fitness for use, the satisfaction of the needs of constituents, or fulfillment of institutions' educational claims (Cheng, 1995).

\subsection{Theoretical Framework for Measuring the Quality of Hospitality and Tourism Programs}

Horng, Teng and Baum (2009) developed an instrument to measure the quality of hospitality and tourism programs. Though the aim of this study is not to make an evaluation at program level, the six quality standards identified in their conceptual framework provides a sound structure to collectively assess and discuss China's vocational education in hospitality and tourism. Horng, Teng and Baum's quality framework was developed based on two well-known evaluation models: Context-Input-Process-Product (CIPP) and Malcolm Baldrige National Quality Award MBNQA. CIPP, proposed by Stufflebeam (2000), was a comprehensive instrument used to conducting and reporting evaluations in academic services. As its name suggested, this model consisted of four interrelated types of evaluation: context, input, process and product. Context evaluations identify goals and priorities and assess the outcomes based on needs, problems and opportunities. Input evaluations judge possible alternatives to achieve stated goals so as to better plan programs and allocate resources. Process evaluations refer to plan execution and outcome assessment. Lastly, product evaluations are used to monitor process and determine effectiveness by measuring intended and unintended outcomes.

MBNQA is a quality award model widely implemented in the business sector. Its focus of customer satisfaction and performance excellence was later applied in education field (National Institute of Standards and Technology, 2007). In academic, seven criteria were developed to evaluate educational quality, including: a) leadership, b) strategic planning, c) student, stakeholder and market focus, d) measurement, analysis and knowledge management, e) workforce focus, f) process management, and g) results.

Horng, Teng and Baum's preliminary quality framework integrated the conceptions of CIPP and MBNQA as well as the evaluation criteria in reputable accreditation systems, namely ACPHA in the U.S., TedQual 
certification in the WTO, QAA in the U.K., and NRPA in the U.S. Dimensions and indicators in their instrument were then confirmed, deleted or refined by focus group discussion conducted in Taiwan. The six finalized dimensions, according to their relative importance to overall quality, were: curriculum and instruction; faculty; strategic planning; administrative management; student achievements; and resources (see Figure 1).

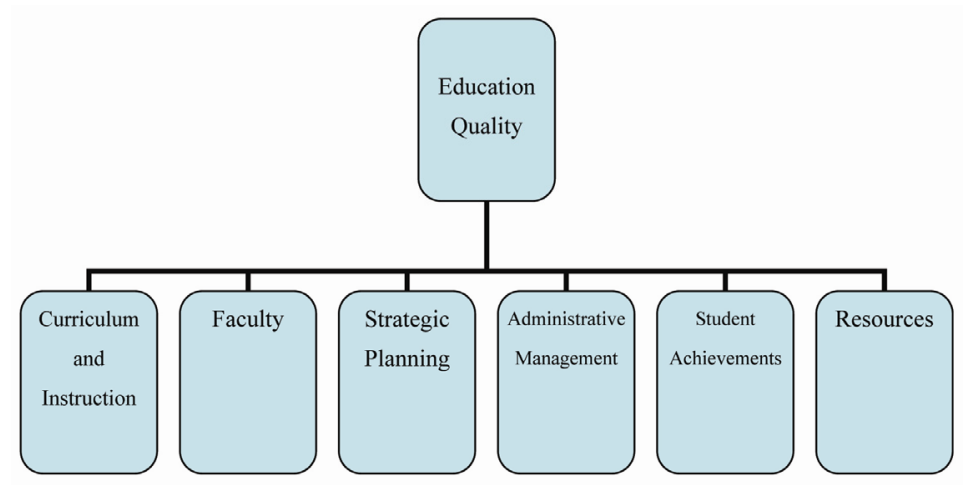

Figure 1. Quality framework for measuring the quality of hospitality and tourism programs

Source: Adopted from Horng, Teng and Baum (2009).

Curriculum and instruction fall in one category, which is the most important contributor to quality education. Curriculum concerns whether the design of curriculum and the courses are in line with the program aims and objectives, current trends, program development features and so on. Instruction refers to teaching and learning, for example, how effective faculty members' teaching can achieve set learning outcomes and whether they can apply their research, counseling, and/or industrial experience to the courses they are assigned to teach. Faculty is ranked as the second important component, which includes teachers' quality and their teaching performance. Teachers' quality concerns faculty member's experience in the field of hospitality, tourism, and/or leisure as well as his/her specializations. It also considers whether teacher's specializations mesh with the program aims and whether the courses assigned to teachers fit their expertise. Teacher's performance is evaluated according to the project sponsorships he/she obtains from the institute and how active the faculty member participate in professional activities. Strategic planning refers to the institute's vision, mission, aims and objectives, whether these elements are explicitly stated and whether the faculty members and students clearly understand them. The other facet of strategic planning is about self-improvement. For continuous improvement, it is important that the institute sets up mechanism to evaluate its operation periodically and collects feedback from its stakeholders Administrative management involves both of administrative leadership and student management, for example, the leadership of the department head, the work efficiency of administrative staff, constant update students on new policies, regulations and announcements, etc. Student achievements include students and graduates' performance as well as alumni feedback. Lastly, resources are considered as the least determinant to quality education. Resources cover the variety and management of training facilities (e.g., mock-up hotel room, demonstration kitchen) and space.

\subsection{China's Vocational Education in Hospitality and Tourism}

China's economy has grown very rapidly since Den Xiao-Ping implemented economic reform, literally "Reform and Opening Up", in 1978. With the significant increase of international tourists and businessmen, the tourism industry has developed rapidly since then and at the same time provided impetus to the development of hospitality and tourism education. Jiangsu Provincial Tourism School, the first hospitality educational institution in China, was established in 1978. A year later, The Shanghai Institute of Tourism was set up, which was the first institution of higher education in tourism and hospitality. As of today, the hospitality and tourism education in China has considerably expanded in terms of number of schools, student pool and diversity of programs. As exhibited in Table 1, the number of institutes grew from 845 in 1996 to 2208 in 2011 and the total number of students reached around 1,083,335 in 2011. 
Table 1. Number of institutions and students of hospitality and tourism education in China 1996-2011

\begin{tabular}{lll}
\hline Year & Institutions & Students \\
\hline 1996 & 845 & 204,263 \\
1997 & 770 & 224,275 \\
1998 & 909 & 233,797 \\
1999 & 1187 & 276,429 \\
2000 & 1195 & 327,938 \\
2001 & 1152 & 342,793 \\
2002 & 1113 & 417,022 \\
2003 & 1207 & 459,000 \\
2004 & 1313 & 578,622 \\
2005 & 1336 & 566,493 \\
2006 & 1703 & 734,854 \\
2007 & 1641 & 773,757 \\
2008 & 1775 & 844,604 \\
2009 & 1733 & 952,438 \\
2010 & 1968 & $1,083,358$ \\
2011 & 2208 & $1,083,335$ \\
\hline
\end{tabular}

Source: CNTA, 1996-2012.

\section{Methodology}

Both secondary data and primary data were utilized to help answer the research question. At first, content analysis was implemented to analyze, compare and synthesize documented information collected from the published academic journals, government websites and publications.

Primary data were then collected through in-depth interviews with academics, industrial managements and administrators in the public educational department. Due to time and resources constraints, twelve interviews were conducted (four from respective sector) and interviewees were selected by convenience sampling. The following interview questions were structured based on six dimensions, i.e. strategic planning, curriculum and instruction, resources, faculty, student achievement and administrative management. The interview was guided by the following open-ended questions:

1) What is your opinion on China's vocational education in terms of strategic planning?

2) What is your opinion on China's vocational education in terms of curriculum and instruction?

3) What is your opinion on China's vocational education in terms of resources?

4) What is your opinion on China's vocational education in terms of faculty?

5) What is your opinion on China's vocational education in terms of student achievements?

6) What is your opinion on China's vocational education in terms of administrative management?

The interview was conducted in Chinese over the telephone phone and then transcribed into English. Its duration was approximately 30 minutes. The interview served two functions in this study. It helped underpin the findings of data analysis on relevant document and supplements more precise and complete information on the study matter.

\section{Data Analysis}

\subsection{Strategic Planning}

With the rapid development of hospitality and tourism industry in China, the number of vocational institute offers hospitality and tourism programme is increasing sharply. As told by one of the respondents, an officer of the provincial education bureau, almost every vocational institute has hospitality and tourism programs. However, such expansion has resulted in scattering of educational input and duplicate investment. As a result, efficiency can barely be achieved in most of the institutes and the limited educational input cannot be fully utilized. As suggested by an official from the government:

An accreditation system for hospitality and tourism programs is not quite strict. A lot of hospitality programs are not qualified. 


\subsection{Resources}

The study revealed that inadequate education resource input is a challenge facing by hospitality and tourism programme in vocational institute in China. Due to tight budget and the cost of constructing hospitality teaching laboratories and other training facilities is relatively higher comparing with the investment of other subjects, very limited financial resources have been invested for improving teaching facilities and conditions. In the meanwhile, hospitality and tourism programme in most of institutes is quite new and still under developing, they have no close connection with the industry to provide enough opportunities for students to complete their internships. As mentioned by one of the respondents:

Building up a hotel teaching laboratory normally cost a lot and some of the non-government institutes even have no teaching lab.

\subsection{Curriculum and Instruction}

The result of the study shows that the hospitality and tourism curriculum has not been developed properly. Because of the great demand for manpower in tourism industry since 1990s, a number of vocational institute established hospitality and tourism programmes by reconstructing related disciplines. These programmes set up and curriculum were developed using existing resources of their previous disciplines without rational design principles and feasible studies. Therefore, hospitality and tourism programs from different institute vary greatly. Graduate from hospitality and tourism programs of different institutes may have acquired different ranges of knowledge: some are very familiar with the tourist attractions in China, while others are well acquainted with Chinese history and tourism biographies. Apart from this, although the current curriculum design involves practical training as a necessary part during students' three-year study, practical training only accounts for a very small part and only happens last year of their study. As commented by an experienced educator who has fundamental industry experiences:

A combination of theory learning and practical training will be better for students to apply they have learned in the classroom to the working environment. In Hong Kong, hospitality students in vocational training school are required to undergo a certain period of practical training at the end of every module.

\subsection{Faculty}

It can be found from the study that the lack of qualified hospitality educators is another issue. Because of short history and rapid growth of hospitality programme in vocational institute, a certain number of hospitality teachers are from other discipline such as language, management, history etc. and their educational background vary greatly. In the meanwhile, some of the instructors who have related hospitality and tourism degrees from university have never worked in hospitality industry and have no idea about the practices of the industry. However, due to the restriction of education policy in China, those experienced industry expertise can hardly be a teacher as it is very difficult for them to achieve professional requirements like education qualification and research achievement. As expressed by one of the presidents from a vocational institute:

None of hospitality instructors at our institute have related industry experiences. However, it is really controversial that people with industry experience are not allowed to be employed.

\subsection{Student Achievement}

The respondents from industry pointed out that most of students' performance is not satisfactory. It is revealed in the study that most of students graduated from hospitality programme do not have much hands-on experiences and realistic evaluation of actual working experiences as they received no or very few practical training during their three-year study. So they may not be able to work independently when they join the industry after graduation. Apart from this, entry requirement for the programme is another reason causing students' unsatisfactory performance. According to the interview, no special entry requirement is needed for applicants who would like to take hospitality and tourism programme. And entry requirement for hospitality programme is relatively lower comparing with other programmes or majors in the same institute. This is quite different from overseas hospitality vocational institute in which the applicants need to be interviewed and communication skills, learning attitude and knowledge of hospitality of applicants will also be taken into consideration.

\subsection{Administrative Management}

In most of the vocational institute, hospitality and tourism programs are dominated by non-tourism disciplines, such as business, management, language, economic, etc. It may indicate that the scope of hospitality and tourism programs is limited and that they cannot meet the special requirements of the industry. 


\section{Conclusion and Implications}

The study evaluates the hospitality and tourism programme in vocational institute in China in terms of six dimensions, i.e. strategic planning, curriculum and instruction, resources, faculty, student achievement and administrative management. The results have revealed that hospitality and tourism programme in vocational institute in China is facing a lot of issues and challenges. To achieve a better quality of hospitality and tourism programme, efforts should be made in the following area:

1) To review curriculum design of hospitality and tourism programmes

Currently, curriculum for hospitality and tourism programmes is developed by education officials and academia without considering the requirement for labor forces in the industry and graduates can't meet the industry needs. Therefore, the industry experts should be involved in the process of curriculum design. Furthermore, practical training should be put more weight than classroom lectures in vocational institute for equipping students with practical skills and techniques before joining the industry after graduation.

2) To build up a team of qualified instructors

Considering that most of instructors don't have industry experiences, industry training should be given to the instructors on monthly or annual basis. Moreover, the schools should invite practitioners from the industry as guest lecturer or even teach some practicum courses. This may help students to shorten the gap between the expectation and the reality.

3) To strengthening cooperation and interaction with the industry

Vocational institute which offers hospitality and tourism programme should develop close relationships with industry practices by offering tailor-made training programs and participating in consultancy and management of hospitality and tourism firms. In turn, institutions can gain financial support from the industry and form a win-win relationship with the tourism business ( $\mathrm{Du}, 2003)$.

\section{4) To build up strict accreditation criteria}

As discussed above, a lot of hospitality and tourism programs are not qualified in terms of quality of instructors, facilities and curriculum. Therefore, stricter accreditation system should be build up for those schools who offer hospitality and tourism programs, Furthermore, schools have partnerships with non-government organization such as UNESCO, to improve their management system (Luo, Lee, \& Qiu, 2015).

5) To set entry requirements for the intake of students

Entry interview is definitely a must for students who would like to take hospitality and tourism course. Personal attributes and attitude is critical for hospitality industry, setting up stricter requirements for the students could somehow guarantee the quality of the graduates which could meet the industry needs. On the other hand, as mentioned, some of the students take hospitality course only because they don't have any other choices. Entry interview can make sure the students have proper intention then ensure their future achievements.

Hospitality industry relies very much on the support of hospitality and tourism education. Although tourism education in China had made great contributions to the development of tourism industry in the past years, it still lags behind the rapid progress of the industry in terms of curriculum design, qualifications of instructors, etc. Similarly, urbanization would be a key factors influence on tourism development with city resident education level (Zhang, Luo, Xiao, \&Denizci Guillet, 2013; Luo, Lee, \& Qiu, 2015). Evaluating the quality of hospitality and tourism education programme accurately has become increasingly important for the growth of hospitality and tourism industry.

\section{References}

Barrows, C. W. (1999). Introduction to hospitality education. In C. W. Barrows \& R. H. Bosselman (Eds.), Hospitality Management Education. Binghamton, New York: Haworth Hospitality Press.

Chang, T. Y., \& Hsu, J. M. (2012). Development framework for tourism and hospitality in higher vocational education in Taiwan. Journal of Hospitality, Leisure, Sport and Tourism Education, 9(1), 101-109.

Chen, K. C., \& Groves, D. (1999). The importance of examining philosophical relationships between tourism and hospitality curricula. International Journal of Contemporary Hospitality Management, 11(1), 37-42. http://dx.doi.org/10.1108/09596119910250382

China National Tourism Administration (CNTA). (1996-2012). The Yearbook of China Tourism Statistics. Peking: China Travel and Tourism Press. 
Du, J. (2003). Reforms and development of higher tourism education in China. In G. Zhang, X. Wei, \& D. Liu (Eds.), Green book of China's tourism development 2002-2004 (pp. 221-230). Beijing: Social Scientific Literature Press.

Fenich, G. G. (1999). Quality and its Assurance in Hospitality Education. In C. W. Barrows \& R. H. Bosselman (Eds.), Hospitality Management Education. Binghamton, New York: Haworth Hospitality Press.

Grönroos, C. (2007). Service Management and Marketing: Customer Management in Service Competition (3rd ed.). John Wiley \& Sons.

Harvey, L., \& Green, D. (1993). Defining quality. Assessment and Evaluation in Higher Education, 18(1), 9-34. http://dx.doi.org/10.1080/0260293930180102

Hobson, J. S. P. (1999). International perspectives: A comparison of U.S., U.K., and Australian hospitality education and their university systems. In C. W. Barrows \& R. H. Bosselman (Eds.), Hospitality Management Education. Binghamton, New York: Haworth Hospitality Press.

Horng, J. S., Teng, C. C., \& Baum, T. (2009). Evaluating the quality of undergraduate hospitality, tourism and leisure programmes. Journal of Hospitality, Leisure, Sport and Tourism Education, 8(1), 37-54.

Luo, J.M., Qiu, H., \& Lam, C.F. (2015). Urbanization Impacts on Regional Tourism Development: a Case Study in China. Current Issues in Tourism. http://dx.doi.org/10.1080/13683500.2015.1033385.

Luo, J.M., Lee, N., \& Qiu, H. (2015). Education for Sustainable Development in Hong Kong: A Review of UNESCO Hong Kong' Experimental Schools. Public Administration \& Policy: An Asia-Pacific Journal. 18(1), 48-61.

Stear, L., \& Griffin, T. (1991). The relationship between tourism and hospitality: The myths, the reality, the causes and consequences for tourism education. In F. Go (Ed.), New horizons in tourism and hospitality education training and research (pp. 383-394). Conference proceedings, Calgary, Canada.

Stufflebeam, D. L. (2000). The CIPP model for evaluation. In D. L. Stufflebeam, G. F. Madaus, \& T. Kellaghan (Eds.), Evaluation models: Viewpoint on educational and human services evaluation (2nd ed., pp. 279-317). Dordrecht, The Netherlands: Kluwer Academic.

United Nation World Tourism Organization (UNWTO). (2012). International tourism continue to robust growth in 2013. Retrieved March 5, from http://media.unwto.org/en/press-release/2013-01-28/international-tourism-continue-roubust-growth-2013

Zhang, W., \& Fan, X. X. (2005). Tourism higher education in China: Past and Present, Opportunities and Challenges. The Haworth Press, Inc.

Zhang, H., Luo, J.M., Xiao, Q., \& Denizci Guillet, B. (2013). The Impact of Urbanization on Hotel Development: Evidence from Guangdong Province in China. International Journal of Hospitality Management, 34, 92-98. http://dx.doi.org/10.1016/j.ijhm.2013.02.013

\section{Copyrights}

Copyright for this article is retained by the author(s), with first publication rights granted to the journal.

This is an open-access article distributed under the terms and conditions of the Creative Commons Attribution license (http://creativecommons.org/licenses/by/3.0/). 